\title{
Effect of Temperature on the Physical, Electro-Chemical and Adsorption Properties of Carbon Micro-Spheres Using Hydrothermal Carbonization Process
}

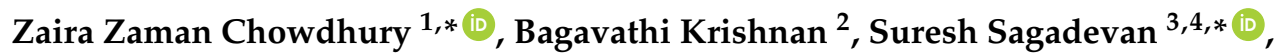 \\ Rahman Faizur Rafique ${ }^{5}$ (1), Nor Aliya Binti Hamizi ${ }^{1}$, Yasmin Abdul Wahab ${ }^{1}$, Ali Akbar Khan ${ }^{1}$, \\ Rafie Bin Johan ${ }^{1}$, Y. Al-douri 1,6,7, Salim Newaz Kazi ${ }^{8}$ (D) and Syed Tawab Shah ${ }^{1}$ \\ 1 Nanotechnology and Catalysis Research Center (NANOCAT), University of Malaya, Kuala Lumpur 50603, \\ Malaysia; aliyahamizi@um.edu.my (N.A.B.H.); yasminaw@um.edu.my (Y.A.W.); \\ aakhan.um.plasma@gmail.com (A.A.K.); mrafiej@um.edu.my (R.B.J.); yarub@um.edu.my (Y.A.-d.); \\ tawab_shah2003@yahoo.com (S.T.S.) \\ 2 Department of Chemical Engineering, University Malaysia Pahang, Pekan Pahang 26600, Malaysia; \\ beggyk@gmail.com \\ 3 Centre for Nanotechnology, AMET University, Chennai 603112, India \\ 4 Centre for Foundation Studies, Department of Physics, National Defense University Malaysia, Kem Sg. Besi, \\ 57000 Kuala Lumpur, Malaysia \\ 5 Rutgers Cooperative Extension Water Resources Program, Rutgers, The State University of New Jersey; \\ New Brunswick, NJ 08901, USA; rahman.rafique@rutgers.edu \\ 6 Physics Department, Faculty of Science, University of Sidi-Bel-Abbes, Sidi-Bel-Abbes 22000, Algeria \\ 7 Department of Mechatronics Engineering, Faculty of Engineering and Natural Sciences, \\ Bahcesehir University, Besiktas, Istanbul 34349, Turkey \\ 8 Department of Mechanical Engineering, University of Malaya, Kuala Lumpur 50603, Malaysia; \\ salimnewaz@um.edu.my \\ * Correspondence: dr.zaira.chowdhury@um.edu.my or zaira.chowdhury76@gmail.com (Z.Z.C.), \\ sureshsagadevan@gmail.com (S.S.); Tel.: +60-102675621 (Z.Z.C.)
}

Received: 18 April 2018; Accepted: 12 July 2018; Published: 6 August 2018

Abstract: This research deals with the effect of the temperature on the physical, thermal, electrochemical, and adsorption properties of the carbon micro-spheres using hydrothermal carbonization (HTC). Until recently, limited research has been conducted regarding the effects of delignification during the HTC process of biomass residues especially Dimocarpus longan. In this regard, lignin was first extracted from the lingo-cellulosic waste of Longan fruit peel (Dimocarpus longan). The holocellulose (HC) separated from lignin and raw biomass substrates (Longan fruit exocarp/peel powder, LFP) were carbonized at different temperatures using water as the green catalyst. Hydrothermal carbonization (HTC) was performed for both of the samples (LFP and HC) at $200^{\circ} \mathrm{C}, 250^{\circ} \mathrm{C}$, and $300^{\circ} \mathrm{C}$ for $24 \mathrm{~h}$ each. The surface morphological structures, the porosity, and the Brunauer-Emmett-Teller (BET) surface area of the prepared micro-spherical carbon were determined. The BET surface areas obtained for HC-based carbon samples were lower than that of the raw LFP based carbon samples. The carbon obtained was characterized using ultimate and proximate analyses. The surface morphological features and phase transformation of the synthesized micro-spherical carbon was characterized by a field-emission scanning electron microscopy (FE-SEM) and X-ray diffraction (XRD) analysis. The results demonstrated that the extraction of lignin could significantly alter the end properties of the synthesized carbon sample. The carbon spheres derived from LFP showed a higher carbon content than the HC-based carbon. The absence of lignin in the holo-cellulose (HC) made it easy to disintegrate in comparison to the raw, LFP-based carbon samples during the HTC process. The carbonaceous samples (LFP-300 and HC-300) prepared at $300{ }^{\circ} \mathrm{C}$ were selected and their adsorption performance for $\mathrm{Pb}$ (II) cations was observed using Langmuir, Freundlich, 
and Temkin linear isotherm models. At $30{ }^{\circ} \mathrm{C}$, the equilibrium data followed the Langmuir isotherm model more than the Freundlich and Temkin model for both the LFP-300 sample and the HC-300 sample. The potential of the synthesized carbon microspheres were further analyzed by thermodynamic characterizations of the adsorption equilibrium system.

Keywords: catalyst; lignin; holo-cellulose (HC); isotherms; thermodynamics; hydrothermal carbonization (HTC)

\section{Introduction}

Ligno-cellulosic biomass is considered to be a renewable, promising, and eco-friendly alternative resource for the preparation of carbon-based chemicals and fuels [1,2]. The existing global supply of carbon depends mainly on fossil fuels (oil, natural gas, and coal), which are limited in quantity. Due to the rapid depletion of fossil energy, using biomass to produce value-added products has elicited great attention from researchers in modern times [3]. Biomass can be converted to yield char or carbon using different thermal, biological, and physio-chemical processes. Among those techniques, hydrothermal carbonization (HTC) is more convenient since it can be performed at comparatively lower temperatures $\left(150{ }^{\circ} \mathrm{C}\right.$ to $\left.350{ }^{\circ} \mathrm{C}\right)$ using acids, bases, metallic salts, or water as a "green catalyst" [4-8]. The overall hydrothermal carbonization (HTC) process is performed under autogenously created pressure inside an autoclave. Lot of complex reactions including condensation, hydrolysis, dehydration, and decarboxylation take place to transform the biomass into a carbon-rich substrate with unique properties [8]. Carbonaceous materials can be produced through thermal treatment of the starting materials such as polysaccharides (cellulose), organic molecules (e.g., furfural), or complex materials (e.g., lingo-cellulosic biomass) with water. The subsequent solid products obtained are enriched with carbon and are known as hydrochars or carbon based on carbon proportions. Depending on the preparation condition, these types of carbon can exhibit attractive physical and electrochemical properties [9-13]. The HTC process is carried out frequently to convert mono-saccharides and oligosaccharides to obtain hydrochars or carbon. Carbon micro-spheres, therefore, can be used as a matrix to fabricate porous carbon after activation [14]. It can even be used to prepare carbon-based composites using a metal or metal oxide catalyst $[15,16]$. Due to the variation in the cellulose and lignin content of several types of biomass residues, the physiochemical properties of hydro-chars or carbon samples prepared from a certain quantity of ligno-cellulosic substrate can vary greatly across different samples.

Thermochemical processes used for an HTC process can convert the compact heterogeneous network of ligno-cellulosic residues into advantageous forms tailored to consumer requirements. The design of an HTC reactor, feedstock composition, reaction parameters (i.e., holding time, temperature, rate of heating, type, and amount of catalyst and pressure), and the physical characteristics of feedstock (particle size and porosities) have a robust impact on the characteristics of the resulting char or carbon samples [17-19]. Hydrothermal carbonization involves the application of aqueous reaction medium, which entails using water as a green catalyst. In that case, the wet biomass can be used, which excludes the pre-drying process before the HTC treatment. The HTC process is more flexible than the dry pyrolysis process. The gaseous products formed during the HTC process are mostly dissolved in the slurry containing char-water mixture.

Cellulose is a complex, crystalline biopolymer made from D-glucose monomers and is the major constituent of raw biomass. Consequently, it is evident that HTC should exemplify an effective technique to transform biomass residues into carbonaceous materials. However, using lingo-cellulosic biomass as a starting precursor is more complex than using simple monosaccharaide or oligosaccharide molecules. The higher degree of structural complexity in biomass can affect the HTC mechanism to a greater extent as well. Biomass contains cellulose, hemicellulose, and a lignin polymer. In plants, the skeleton of the cell walls is built using cellulose. However, the presence of lignin with some 
substances like pectins, proteins, and extraneous substances provides strength to the plants [20]. Hemicellulose is a type of branched polymer that is amorphous and contains many other saccharides including mannose, xylose, arabinose, and galactose. Lignin is a non-polysaccharide and it is a highly stable poly-phenolic aromatic biopolymer. The phenyl-propane units are cross-linked to give lignin. The cellulosic fractions in biomass are intricately bonded with lignin, which provides strength to the plants. Cellulose and hemicellulose are easy to transform while lignin is difficult to treat because, at low temperatures, it is partially degraded [19]. The HTC process was carried out previously for cellulose, eucalyptus sawdust, and barley straw within the temperature range of $220^{\circ} \mathrm{C}$ to $250{ }^{\circ} \mathrm{C}$ for a residence period of $2 \mathrm{~h}$ to $4 \mathrm{~h}[6,7]$. Microcrystalline cellulose and wood sawdust were used earlier to produce nanoparticles, which were later used for electrochemical hydrogen generation [21]. Due to the coverage of lignin, the cellulose inside the crude biomass could be minimally disintegrated. The aqueous medium of the hydrothermal conditions can only partially degrade the cellulose and hemicellulose fraction. Therefore, lignin's existence has negative impacts on the effective transformation of cellulose and hemicellulose into the char sample during the HTC process. The effective surface area also decreases in size due to the presence of lignin. Therefore, removal of lignin with some minor constituents like pectin and wax can enhance the internal surface area for the effective transformation of biomass residues [22,23].

Until recently, limited studies have been carried out to observe the characteristics of char or carbon products resulting from HC (cellulose and hemicellulose) after delignification of raw biomass. To the author's knowledge, no research has been conducted on the extraction of HC from Dimocarpus longan fruit peel and the synthesis of the spherical carbonaceous materials from the raw peel (LFP) using an HTC technique. Dimocarpus longan is commonly known as the longan. It grows abundantly in Asia predominantly in China, Taiwan, Vietnam, and Thailand [24]. In 2010, China produced 1300 million tons of longan. The statistics showed that Vietnam and Thailand also produced approximately 600 million and 500 million tons, respectively [25]. The plants grown in the tropical region belongs to the family of Sapindaceae. The peel or exocarp of longan fruit is lightweight and thin. After extraction of the juicy edible pulp that is mesocarp, the peels are thrown off. Usage of this waste lingo-cellulosic residue for the synthesis of carbon can solve the waste disposal problem as well as add some valuable products for further application in versatile fields. In this work, HC was extracted from LFP and used as the starting material to prepare solid carbon or char using the HTC process. The morphological as well as electrochemical properties with energy content of the HTC-based carbon samples derived from LFP and HC were studied at temperatures of $200{ }^{\circ} \mathrm{C}, 250{ }^{\circ} \mathrm{C}$, and $300{ }^{\circ} \mathrm{C}$. The purpose of this study is to evaluate the impact of eliminating lignin and other minor constituents from the biomass, which ultimately can have significant influence on the properties of the carbon sample obtained by the HTC process using water as a "green catalyst". The synthesized carbon microspheres from LFP and $\mathrm{HC}$ were used for adsorption of $\mathrm{Pb}(\mathrm{II})$ cations from the aqueous system. Equilibrium isotherm and thermodynamic characterizations were done to determine the parameters influencing the sorption process at different temperatures.

\section{Results and Discussions}

\subsection{Effect of Temperature on Physical, Electrochemical, and Thermal Properties of Hydro-Char}

\subsubsection{Yield, Energy Content, $\mathrm{pH}$, Electrical Conductivity, and Ultimate Analysis}

Table 1 illustrates the CHNOS analysis of the precursors (HC and LFP) along with the synthesized sample at different temperatures. A progressive increase in temperature during the HTC process raised the carbon content of a sample, but decreased the oxygen and hydrogen content [26-28]. The $\mathrm{H} / \mathrm{C}$ and $\mathrm{O} / \mathrm{C}$ ratios decreased after carbonization at higher temperatures for both of the samples. The decreased $\mathrm{H} / \mathrm{C}$ ratio was ascribed to the increased rate that the aromatization reactions occurred during the HTC process [29]. Due to a decarboxylation reaction, the $\mathrm{O} / \mathrm{C}$ ratio was decreased. The $\mathrm{H} / \mathrm{C}$ and $\mathrm{O} / \mathrm{C}$ ratios decreased due to dehydration [30]. The $\mathrm{H} / \mathrm{C}$ and $\mathrm{O} / \mathrm{C}$ ratios in the HC-based 
carbon samples decreased more noticeably than those with the LFP powder. This was due to the higher coalification values for the HC-based samples. The yield of the carbon samples was inversely proportional with the carbonization temperature. The yield dropped significantly after the temperature from $200{ }^{\circ} \mathrm{C}$ to $300{ }^{\circ} \mathrm{C}$ for both the precursors increased (HC and LFP), which is illustrated by Table 1 . Thermal degradation of lingo-cellulosic biomass usually occurs at lower temperatures. At higher temperatures, the higher molecular weight organic compounds in the biomass are devolatilized into lower molecular weight compounds along with some gases being produced as well [31]. Dehydration and elimination reactions would proceed faster at higher temperatures, which leads to a decreased char yield for both samples [32-34]. This trend was anticipated since the mass-yield loss at higher temperatures was associated with progressive dehydrogenation and aromatization of the hydrochar sample, which included the subsequent decomposition of inorganic elements [19]. The HTC process is considered an efficient way for densification of the energy of the biomass matrix [35]. From Table 1, it can be observed that the energy content (HHV) of the carbon samples increased with rising HTC temperatures. However, the HC-based carbon samples showed slightly higher values of HHV than the LFP samples. The $\mathrm{pH}$ values obtained for the LFP samples were slightly more acidic than the HC-based samples. The electrical conductivity (EC) increased slightly with rising temperatures, which indicated a high salinity for all of the samples. The results aligned with the previous work conducted on the hydrothermal carbonization of rice husk [36] where the magnitude of the $\mathrm{pH}$ and EC values of the synthesized carbon samples somewhat enhanced with an increasing rate of temperature. This was expected due to the existence of a larger amount of ash residue in the char or carbon sample produced at a higher carbonization temperature [37].

Table 1. Properties of Dimocarpus longan fruit peel powder (LFP) and Holocellulose (HC) with their carbonized samples at different temperatures.

\begin{tabular}{|c|c|c|c|c|c|c|c|c|c|c|c|}
\hline \multirow{2}{*}{ Sample } & \multicolumn{7}{|c|}{ Ultimate or CHNOS Analysis (wt \%) } & \multirow{2}{*}{$\begin{array}{c}\text { Yield } \\
\%\end{array}$} & \multirow{2}{*}{$\begin{array}{c}\text { HHV } \\
\text { MJ-Kg }^{-1}\end{array}$} & \multirow{2}{*}{$\frac{\mathrm{pH}}{-}$} & \multirow{2}{*}{$\begin{array}{c}\mathrm{EC} \\
\mathrm{mS}\end{array}$} \\
\hline & $\mathrm{C}$ & $\mathbf{H}$ & $\mathbf{N}$ & $\mathrm{O}$ & $\mathrm{S}$ & $\mathrm{H} / \mathrm{C}$ & $\mathrm{O} / \mathrm{C}$ & & & & \\
\hline Raw LFP & 32.65 & 10.87 & 2.12 & 54.34 & 0.02 & 0.33 & 1.66 & - & 18.05 & - & - \\
\hline LFP-200 & 40.78 & 7.66 & 2.02 & 49.51 & 0.03 & 0.19 & 1.21 & 56.45 & 18.95 & 4.92 & 0.97 \\
\hline LFP-250 & 52.21 & 4.67 & 1.23 & 41.87 & 0.02 & 0.09 & 0.80 & 43.89 & 19.09 & 5.79 & 1.48 \\
\hline LFP-300 & 70.88 & 3.65 & 1.01 & 26.45 & 0.01 & 0.05 & 0.37 & 33.32 & 25.56 & 5.99 & 1.72 \\
\hline Raw HC & 32.77 & 10.40 & 6.06 & 50.74 & 0.04 & 0.32 & 1.55 & - & 18.46 & - & - \\
\hline HC-200 & 41.88 & 8.35 & 5.12 & 44.63 & 0.02 & 0.20 & 1.06 & 57.45 & 19.61 & 4.85 & 0.91 \\
\hline HC-250 & 53.99 & 5.01 & 2.01 & 38.96 & 0.03 & 0.09 & 0.72 & 48.98 & 20.44 & 5.65 & 1.23 \\
\hline HC-300 & 71.99 & 3.02 & 0.55 & 24.41 & 0.03 & 0.04 & 0.34 & 35.89 & 25.86 & 5.98 & 1.55 \\
\hline
\end{tabular}

\subsubsection{Thermogravimetric/Proximate Analysis}

The thermal stabilities of both LFP and HC samples with their corresponding carbon spheres were investigated using the thermo-gravimetric method and are shown in Figures 1 and 2 for LFPand HC-based carbon, respectively.

The TGA curve showed several stages for the synthesized samples. The initial degradation step occurred at approximately $80^{\circ} \mathrm{C}$ to $120^{\circ} \mathrm{C}$. This was due to the loss of the adsorbed moisture. The subsequent degradation step for LFP occurred between about $200{ }^{\circ} \mathrm{C}$ to $300{ }^{\circ} \mathrm{C}$ and represented the degradation of hemicellulose. At temperatures between $300{ }^{\circ} \mathrm{C}$ and $400{ }^{\circ} \mathrm{C}$, cellulose degradation occurred. It was previously described that the degradation of hemicelluloses somewhat overlapped with the cellulose degradation in biomass. Due to the complex structure of lignin, the degradation of this macromolecule took place within the long temperature range, which started at $200{ }^{\circ} \mathrm{C}$ until $800{ }^{\circ} \mathrm{C}[38,39]$. The presence of the phenyl group made the decomposition of the lignin much more difficult [19]. Compared with untreated LFP, the carbon sample derived from LFP showed higher thermal stability at different temperatures. This phenomenon was earlier observed for the HTC conversion of poplar wood-based samples [30]. 
As illustrated by Table 2, the DTG $\max$ of LFP-200, LFP-250, and LFP-300 were $342.37^{\circ} \mathrm{C}, 355.77^{\circ} \mathrm{C}$, and $369.89{ }^{\circ} \mathrm{C}$, respectively. The amorphous domain of the cellulosic chain as well as the hemicellulose fraction was removed during the hydrothermal carbonization (HTC) process of the LFP samples, which resulted in a higher thermal stability for the prepared carbon samples. With a subsequent increase in temperature, the sample contained a greater proportion of a heat resistant stable form of carbon particles. This was further confirmed by an elemental analysis of the synthesized samples. The percentage of carbon in the LFP sample was initially low, but, after consecutive treatment using the HTC process, the percentage of carbon increased with a rise in temperature (Table 1). The thermal stability of the HC-based hydrochars grew with increasing temperatures. The carbon content in these samples also rose due to an elevated temperature (Table 1). The ash content of the synthesized samples was higher than the raw lingo-cellulosic biomass sample. Compared to LFP-200, LFP-250, and LFP-300, the HC-based samples had more ash and fixed carbon content. At the same time, the volatile component in these samples decreased with an increased temperature. Analogous tendency was observed for the HTC-based carbon as well.

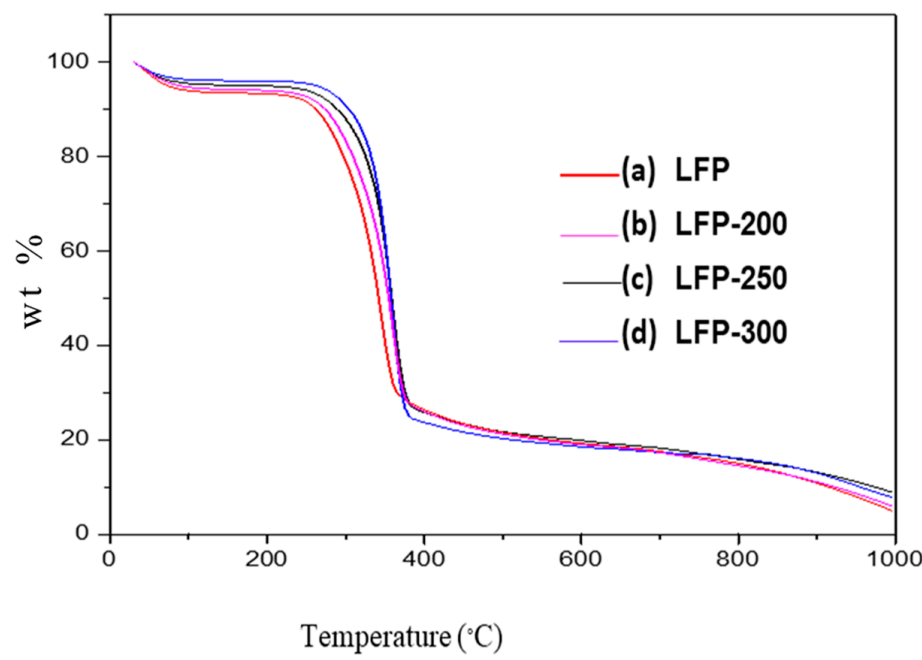

Figure 1. Thermogravimetric curves for (a) Raw Dimocarpus longan peelpowder (LFP) and their corresponding carbon micro-spheres produced at various temperatures (b) LFP-200; (c) LFP-250; and (d) LFP-300.

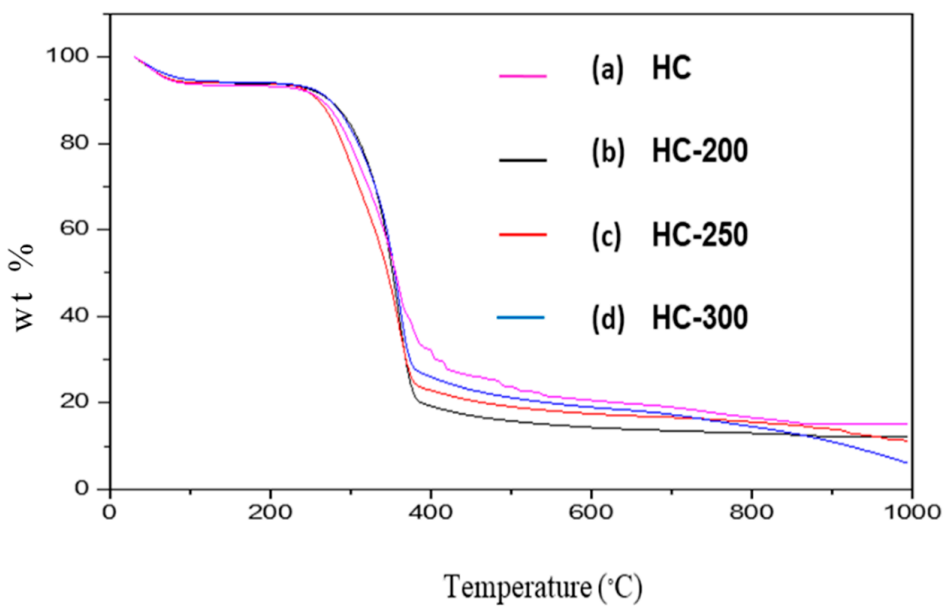

Figure 2. Thermogravimetric curves for (a) Raw Holocellulose (HC) and corresponding carbon micro-spheres produced at various temperatures (b) HC-200; (c) HC-250; and (d) HC-300. 
Table 2. Proximate Analysis of LFP Powder and HC with their Carbonized Samples Resulting from HTC at Different Temperatures.

\begin{tabular}{|c|c|c|c|c|c|}
\hline \multirow{2}{*}{ Sample } & \multicolumn{4}{|c|}{ Proximate Analysis (wt \%) } & \multirow{2}{*}{$D T G_{\text {Max }}$} \\
\hline & Water Content & Volatile Matter & Fixed Carbon & Ash & \\
\hline Raw LFP & 8.07 & 77.88 & 3.38 & 10.67 & 334.78 \\
\hline LFP-200 & 6.78 & 40.67 & 41.54 & 11.01 & 342.37 \\
\hline LFP-250 & 4.25 & 30.32 & 52.23 & 13.20 & 355.77 \\
\hline LFP-300 & 2.89 & 10.78 & 71.55 & 14.78 & 369.89 \\
\hline Raw HC & 9.23 & 76.45 & 2.99 & 11.33 & 324.89 \\
\hline HC-200 & 6.66 & 39.23 & 40.12 & 13.99 & 335.98 \\
\hline HC-250 & 5.89 & 23.32 & 55.87 & 14.92 & 349.90 \\
\hline HC-300 & 2.12 & 11.88 & 69.33 & 16.67 & 357.99 \\
\hline
\end{tabular}

\subsubsection{Surface Morphology Analysis}

The SEM images of raw LFP with extracted HC and their respective carbon samples produced at different temperatures are illustrated by Figures $3 a-d$ and $4 a-d$, respectively. The surface of the wood powder was comparatively rough with some cracks. However, after hydrothermal carbonization (HTC) at different temperatures, some micro-spherical carbon was deposited on the surface of the LFP. The HTC process degraded the cellulose and hemicellulose components substantially to produce carbon microspheres on the surface of the raw peel powder [30,39]. Nevertheless, the lignin content of the biomass was difficult to degrade at lower temperatures $[6,9,21]$. With an increasing temperature, the number of carbon microspheres rose but the size of the carbon microspheres was reduced. At lower temperatures, the LFP particles were fragmented and showed the development of comparatively large, irregularly-shaped carbon microspheres (Figure 3b; see the LFP-200 sample). Comparatively, more carbon microspheres were formed on the surface of the samples called LFP-250 and LFP-300. 

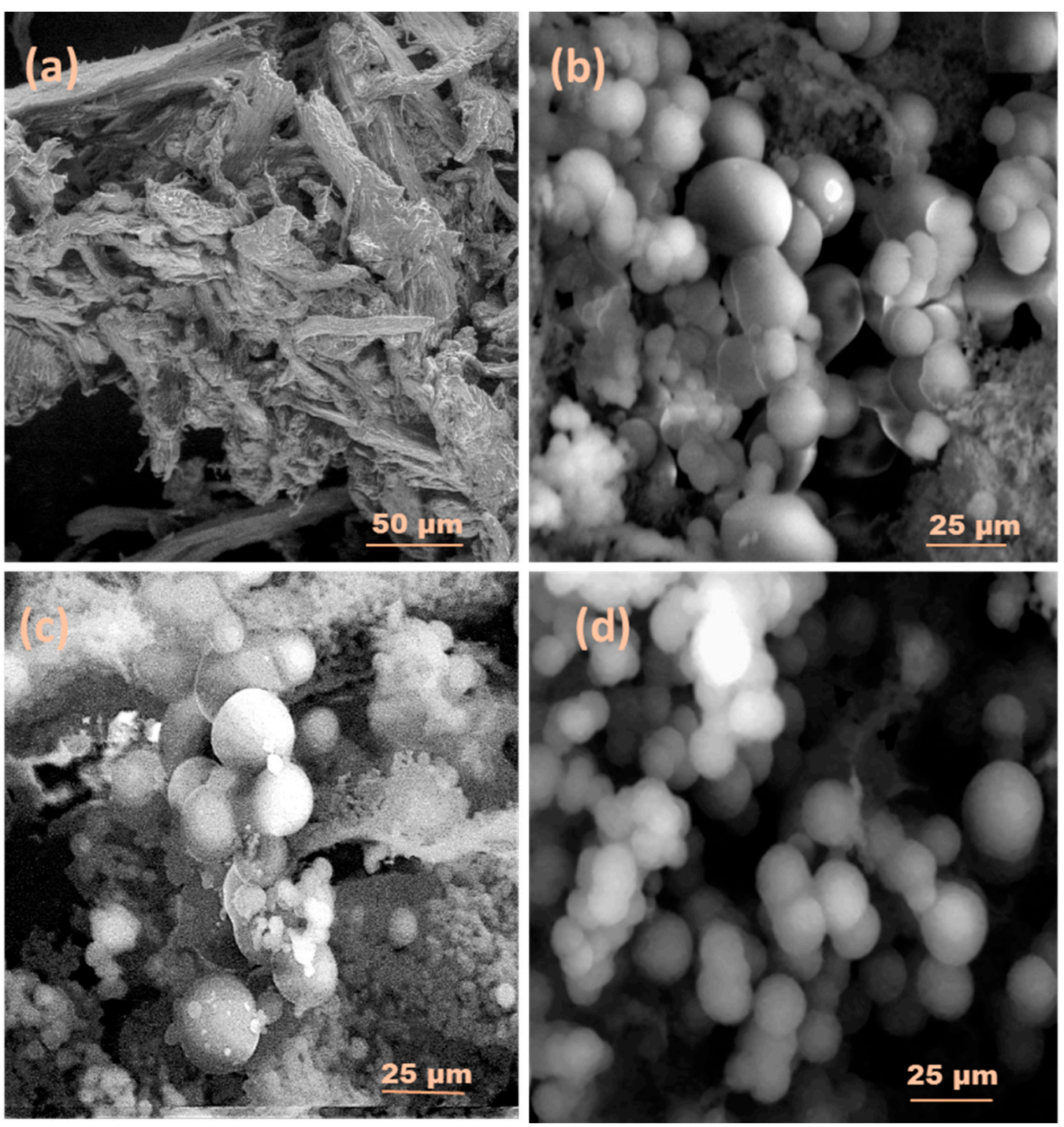

Figure 3. SEM images of (a) Raw Dimocarpus longan peel powder (LFP) and their corresponding carbon micro-spheres (b) LFP-200; (c) LFP-250; and (d) LFP-300 produced at various temperatures.

The HC extracted from the LFP powder was fibrillated. The entire skeleton of the extracted HC was covered by carbon microspheres of varying sizes. The proportion of these carbon microspheres increased successively with a growth in temperature from $200{ }^{\circ} \mathrm{C}$ to $300^{\circ} \mathrm{C}$ during the HTC process (HC-200, HC-250, and HC-300). Compared to LFP-based carbon samples, the number of carbon microspheres in HC-based samples was greater. Furthermore, the sizes of the carbon microspheres were comparatively smaller for HC-based samples. This clearly reflected the presence of lignin in LFP, which made it more difficult to be carbonized completely in comparison with the HC, which contained only a mixture of cellulose and hemicellulose. 

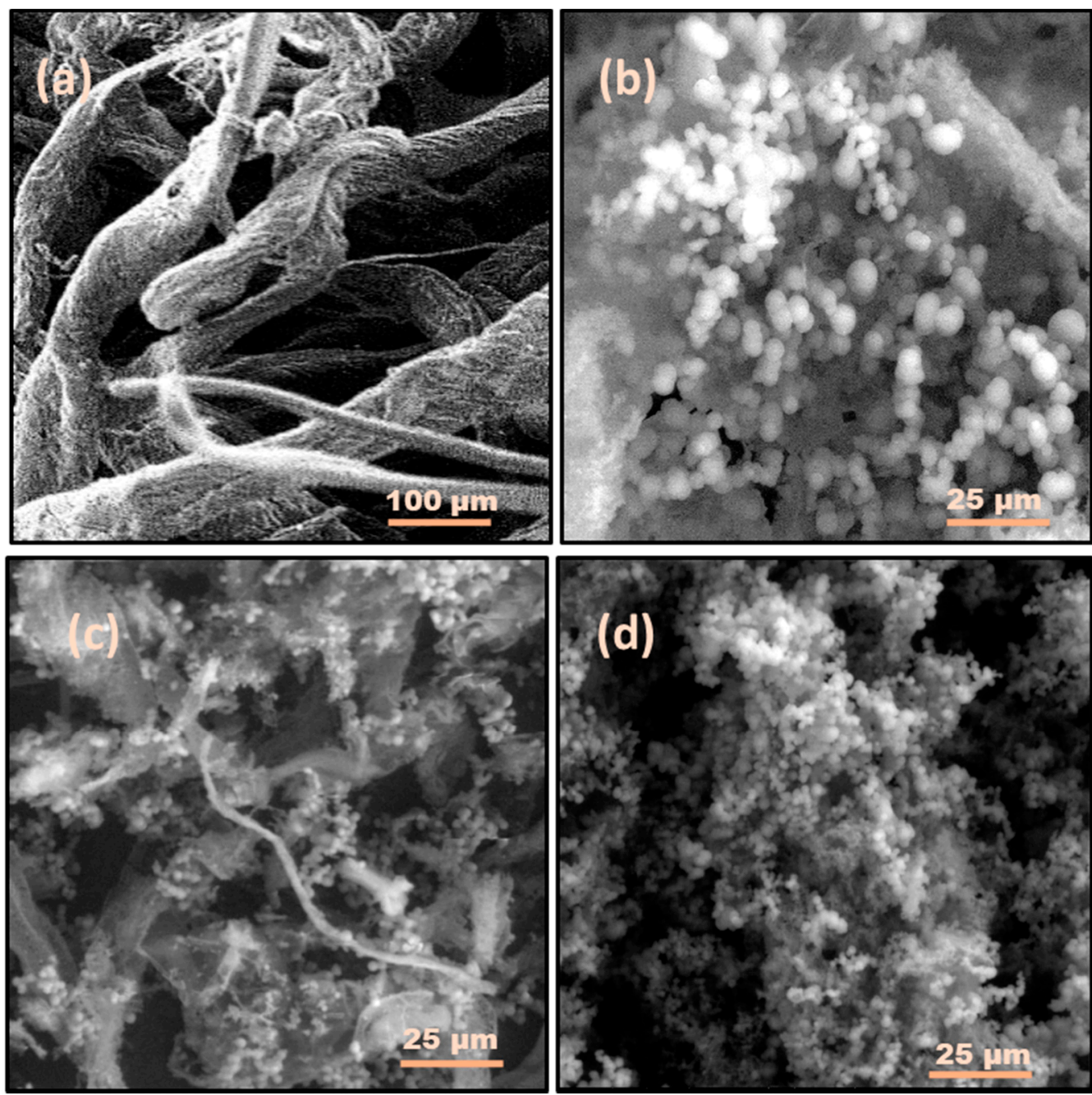

Figure 4. SEM images of (a) Raw Holocellulose (HC) and corresponding carbon micro-spheres: (b) HC-200; (c) HC-250; and (d) HC-300 produced at various temperatures.

\subsubsection{Surface Area and Porosity Analysis}

Figure 5A,B display the $\mathrm{N}_{2}$ adsorption isotherms for LFP-based and HC-based hydrochars, respectively. The surface area of HC-based carbon samples was slightly less. HC-based carbon spheres had poor porosity in comparison with the LFP-based samples. At lower temperatures, both the samples showed comparatively reduced surface areas, which was due to the inadequate carbonization. However, the isotherm obtained for both types of carbon samples were obtained at higher temperatures, which could be classified as an intermediate between type I and type II isotherms [40]. Near the relative pressure of approximately 0.9 , the curve showed an upward trend. This indicated that the obtained carbon samples contained virtually no framework of confined pores [41]. The presence of inter-particle voids caused an increase in the surface area [42]. The type of starting material and temperature of the process can control the amount of pores due to the cracking of the basal structural sheets of the carbon particles [43,44]. Due to incomplete carbonization at lower temperatures during the HTC process, the pores were clogged by the tarry substances. Treatment at higher temperatures caused selective elimination of those components by volatilization, which resulted in a higher pore volume. Higher temperatures further led to de-polymerization reactions, which increased the surface area of both types of carbon spheres [45]. 

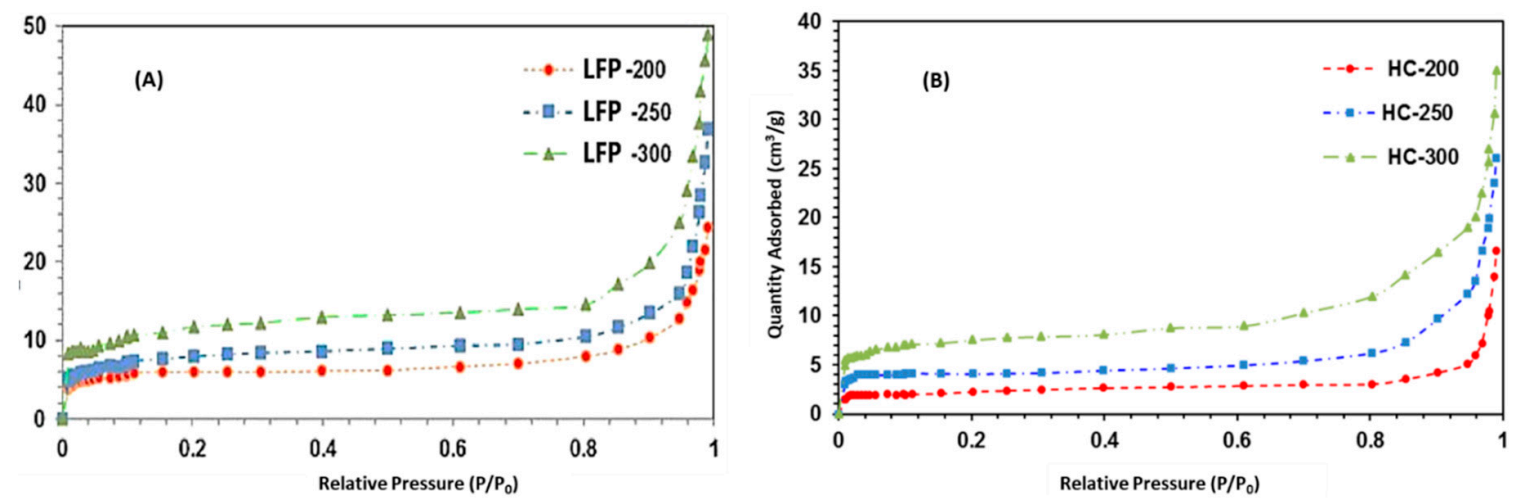

Figure 5. BET Isotherms of (A) LFP-200, LFP-250, and LFP-300; (B) HC-200, HC-250, and HC-300.

The textural parameters determined for both starting materials with corresponding carbon micro-spheres are listed in Table 3.

Table 3. Pore characteristics of Dimocarpus longan peel powder (LFP) and Holocellulose (HC) with carbonized samples resulting from hydrothermal treatment (HTC) at different temperatures.

\begin{tabular}{|c|c|c|c|c|}
\hline Sample & BET Surface Area $\left(\mathrm{m}^{2} / \mathrm{g}\right)$ & $\begin{array}{l}\text { BJH Cumulative Adsorption } \\
\text { Surface Area }\left(\mathrm{m}^{2} / \mathrm{g}\right)\end{array}$ & $\begin{array}{l}\text { Total Pore Volume } \\
\times 10^{-3}\left(\mathrm{~cm}^{3} / \mathrm{g}\right)\end{array}$ & $\begin{array}{c}\text { Average Pore } \\
\text { Diameter (nm) }\end{array}$ \\
\hline Raw LFP & 3.02 & 1.04 & 0.022 & 0.56 \\
\hline LFP-200 & 9.76 & 8.88 & 0.036 & 3.23 \\
\hline LFP-250 & 13.65 & 11.09 & 0.055 & 4.98 \\
\hline LFP-300 & 18.32 & 15.77 & 0.068 & 8.98 \\
\hline Raw HC & 1.51 & 1.02 & 0.013 & 0.22 \\
\hline HC-200 & 5.98 & 4.77 & 0.021 & 1.23 \\
\hline HC-250 & 7.12 & 5.43 & 0.034 & 2.12 \\
\hline HC-300 & 10.76 & 8.88 & 0.046 & 5.67 \\
\hline
\end{tabular}

\subsubsection{Crystallinity or X-ray Diffraction (XRD) Analysis}

The XRD spectra for the raw LFP sample with the extracted HC and their corresponding carbon produced at different temperatures are illustrated by Figure 6A,B, respectively. The two sharp narrow peaks in Figure $6 \mathrm{~A}, \mathrm{~B}$ at $2 \theta$ values of around $16.5^{\circ}$ and $22.6^{\circ}$ show the presence of amorphous and crystalline regions of cellulose in the raw LFP and HC samples. The crystallinity obtained for HC was $58.68 \%$, which was higher than that of the LFP peel powder $(46.28 \%)$. The increasing trend of crystallinity in $\mathrm{HC}$ was due to the delignification and the partial removal of hemicellulose from the LFP powder during the preparation of HC. When both the LFP and HC samples were hydrothermally carbonized, the resulting carbon showed different XRD patterns. When the temperature increased from $200{ }^{\circ} \mathrm{C}$ to $300^{\circ} \mathrm{C}$, the peaks around $22^{\circ}$ to $24^{\circ}$ broadened in both the samples of LFP-based and HC-based carbons. 


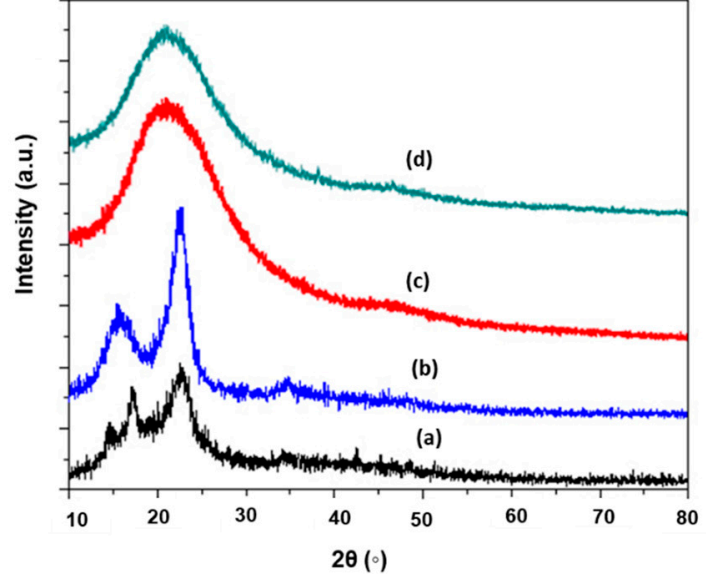

(A)

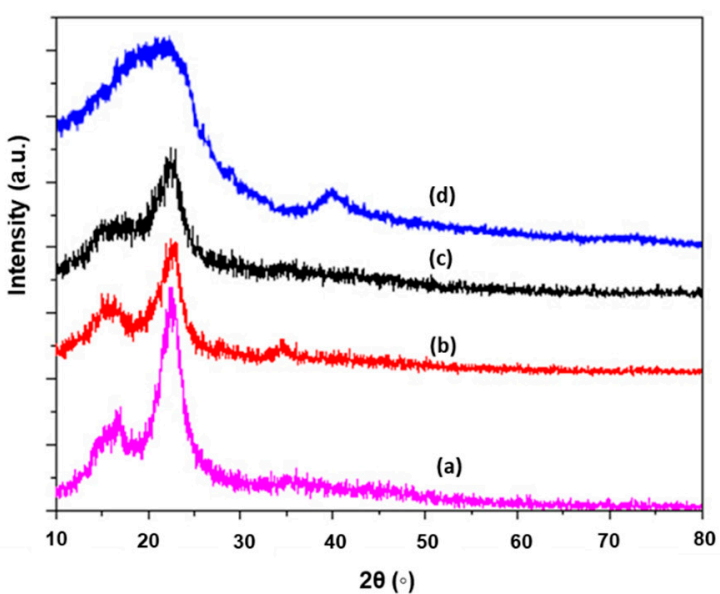

(B)

Figure 6. (A) X-ray Spectra of Dimocarpus longan peel powder (LFP) and the corresponding carbon micro-spheres produced at various temperatures: (a) LFP Powder; (b) LFP-200; (c) LFP-250; and (d) LFP-300 produced at various temperatures; (B) X-ray Spectra of HC and their corresponding carbon micro-spheres produced at various temperatures: (a) HC; (b) HC-200; (c) HC-250; and (d) HC-300.

For LFP-based and HC-based carbons, the intensities of these two peaks decreased slightly with a rise in temperature [46]. The amorphous texture of the prepared carbon samples (LFP-300, HC-250, and HC-300) was confirmed by the absence of a sharp peak in the XRD spectra [47]. The XRD patterns of LFP-based carbon showed that hydrothermal carbonization at lower temperatures could not disrupt the crystalline texture of cellulose completely. In prior research, this phenomenon was similarly observed for sawdust-based, wheat straw-based, and corn stalk-based hydro-carbon and potassium hydroxide $(\mathrm{KOH})$-treated hydro-char [42].

Compared to LFP-250, the sharp peak around $16^{\circ}$ was completely absent in HC-250. The presence of lignin in LFP-250 made it difficult for the sample to be carbonized more completely than the HC-250 sample.

\subsection{Equilibrium Adsorption Isotherm and Thermodynamic Parameters Evaluation}

The adsorbent-adsorbate reaction mechanism under the equilibrium system can be illustrated by using different isotherm models. In this research, a linear regression analysis was carried out for synthesized carbon microspheres at different temperature for both types of hydrochar samples. The linear form of the Langmuir isotherm can be represented by the equation below [47].

$$
\frac{C_{e}}{q_{e}}=\frac{1}{q_{\max } K_{L}}+\frac{1}{q_{\max }} C_{e}
$$

In Equation (1), $q_{m}(\mathrm{mg} / \mathrm{g})$ represents the maximum monolayer adsorption capacity. $C_{e}(\mathrm{mg} / \mathrm{L})$ is the equilibrium concentration of the adsorbate at a liquid phase and $q_{e}(\mathrm{mg} / \mathrm{g})$ is the equilibrium amount of adsorbate adsorbed over the adsorbent's surface. $K_{L}$ is the Langmuir adsorption constant $\left(\mathrm{L} / \mathrm{mg}\right.$ ) related to the binding energy for sorption. $R_{L}$ is the separation factor obtained from the Langmuir equation [47].

$$
R_{L}=\frac{1}{1+K_{L} C_{0}}
$$

For this study, $R_{L}$ values are determined for a maximum initial concentration under investigation $(150 \mathrm{mg} / \mathrm{L})$. If the magnitude of RL values are within 0 to 1 , then the adsorption process is favorable. 
The Freundlich isotherm is frequently used to illustrate the surface heterogeneity of the process with multilayer formation over the surface [48]. The linear form of the Freundlich isotherm is shown below.

$$
\ln q_{e}=\ln K_{f}+\frac{1}{n} \ln C_{e}
$$

In Equation (3), $K_{f}(\mathrm{mg} / \mathrm{g})$ is the affinity factor of the adsorbate towards the adsorbent and $1 / n$ represents the intensity of adsorption, respectively [48].

Table 4 summarizes the values obtained for isotherm parameters in LFP-300 and HC 300 samples. The linear form of the Temkin Isotherm can be expressed by the equation below [45].

$$
q_{e}=\frac{R T}{b} \ln K_{T}+\frac{R T}{b} \ln C_{e}
$$

In this paper, $R T / b=B(\mathrm{~J} / \mathrm{mol})$, denotes the Temkin constant, which depicts the heat of the sorption process while $K_{T}(\mathrm{~L} / \mathrm{g})$ reflects the equilibrium binding constant. $R(8.314 \mathrm{~J} / \mathrm{mol} \mathrm{k})$ is the universal gas constant and $\mathrm{T}^{\circ}(\mathrm{K})$ is the absolute solution temperature [49].

The magnitude of the Langmuir separation factor, $R_{L}$, and the Freundlich exponent $1 / n$ are below one (Table 4). This represents favorable adsorption processes [50]. Furthermore, the Langmuir monolayer adsorption capacity $\left(q_{\max }\right)$ grew with a successive increase of the temperature from $30{ }^{\circ} \mathrm{C}$ to $50{ }^{\circ} \mathrm{C}$, which showed the endothermic nature of the sorption process [50,51]. Similar trend have been followed by untreated and acid-activated corncob biomass for the sorption of divalent $\mathrm{Mn}^{2+}$ cations [51]. It was further validated by thermodynamic characterization of the system. The linear regression obtained for different isotherm models is illustrated by Figures 7 and 8 . 
Table 4. Isotherm Model parameters at Different Temperature for LFP-300 and HC-300.

\begin{tabular}{|c|c|c|c|c|c|c|c|c|c|c|c|}
\hline \multirow[t]{2}{*}{ Sample } & \multirow{2}{*}{$\begin{array}{c}\text { Temperature } \\
{ }^{\circ} \mathrm{C} \\
\end{array}$} & \multicolumn{4}{|c|}{ Langmuir Isotherm } & \multicolumn{3}{|c|}{ Freundlich Isotherm } & \multicolumn{3}{|c|}{ Temkin Isotherm } \\
\hline & & $q_{\max }(\mathrm{mg} / \mathrm{g})$ & $K_{L}(\mathrm{~L} / \mathrm{mg})$ & $R_{L}$ & $R^{2}$ & $K_{F}(\mathrm{mg} / \mathrm{g})(\mathrm{L} / \mathrm{mg})^{1 / n}$ & $1 / n$ & $R^{2}$ & $B$ & $K_{T}(\mathrm{~L} / \mathrm{mg})$ & $R^{2}$ \\
\hline \multirow{3}{*}{ LFP-300 } & 30 & 20.40 & 0.1658 & 0.038 & 0.998 & 4.474 & 0.401 & 0.879 & 3.964 & 4.5815 & 0.935 \\
\hline & 40 & 21.27 & 0.2143 & 0.030 & 0.999 & 7.027 & 0.263 & 0.967 & 3.766 & 25.621 & 0.986 \\
\hline & 50 & 22.72 & 0.3135 & 0.021 & 0.998 & 6.461 & 0.324 & 0.907 & 3.781 & 84.576 & 0.978 \\
\hline \multirow{3}{*}{ HC-300 } & 30 & 17.03 & 0.1691 & 0.035 & 0.992 & 1.229 & 0.534 & 0.932 & 4.002 & 3.2861 & 0.989 \\
\hline & 40 & 17.54 & 0.2132 & 0.026 & 0.918 & 1.122 & 0.584 & 0.968 & 3.727 & 3.7488 & 0.933 \\
\hline & 50 & 18.59 & 0.3015 & 0.032 & 0.909 & 1.052 & 0.434 & 0.978 & 3.702 & 2.491 & 0.903 \\
\hline
\end{tabular}



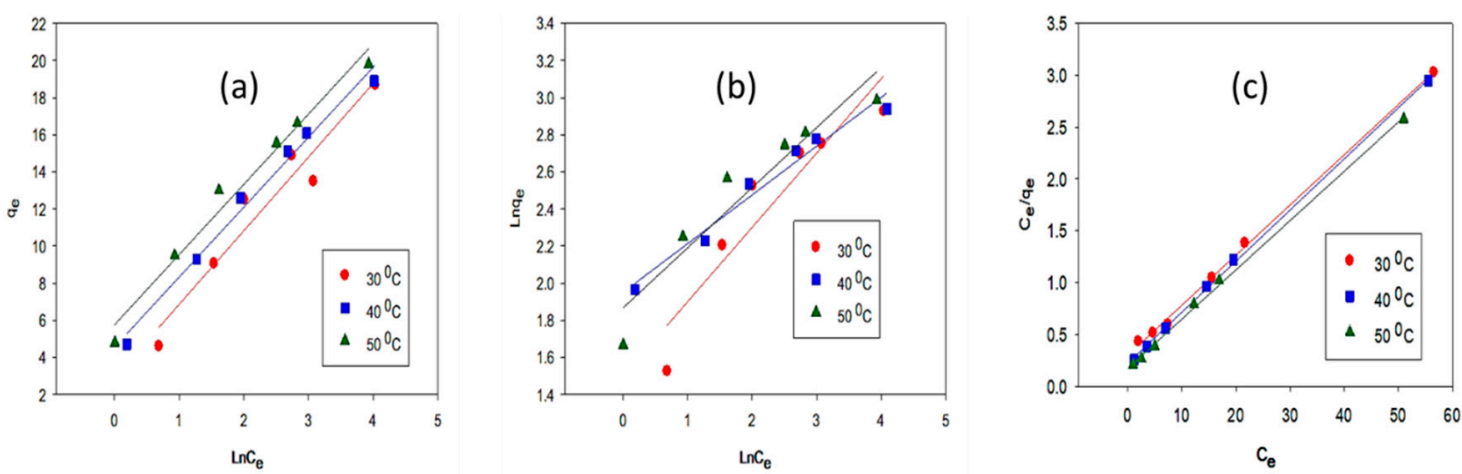

Figure 7. Linear Regression Analysis of (a) Langmuir; (b) Freundlich; and (c) Temkin Isotherm model at different temperature for LFP-300.
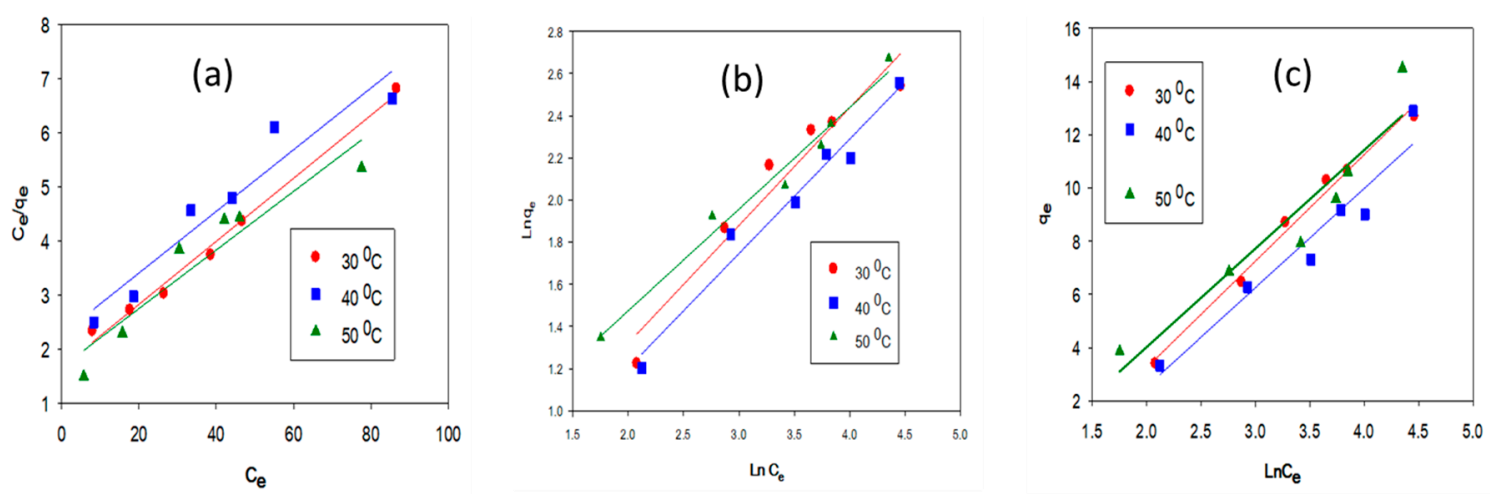

Figure 8. Linear Regression Analysis of (a) Langmuir; (b) Freundlich; and (c) Temkin Isotherm model at different temperatures for LFP-300.

Thermodynamic parameters including Gibbs free energy $\left(\Delta G^{\circ}\right)$, enthalpy $\left(\Delta H^{\circ}\right)$, and entropy $\left(\Delta S^{\circ}\right)$ of the equilibrium system were evaluated for LFP-300 and HC 300 [52]. The linear equations used for this are shown below.

$$
\begin{gathered}
\operatorname{Ln} K_{L}=\frac{\Delta S}{\Delta R}-\frac{\Delta H}{R T} \\
\Delta G=R T \operatorname{Ln} K_{L}
\end{gathered}
$$

In the equations above, constant $K_{L}(\mathrm{~L} / \mathrm{mg})$ was earlier determined using the Langmuir equation at three different temperatures. $R$ is the universal gas constant $(8.314 \mathrm{~J} / \mathrm{mol} \cdot \mathrm{K})$ and $T$ is the absolute temperature in Kelvin scale. The $\ln K_{L}$ versus the $1 / T$ plot was used to calculate thermodynamic parameters and it is listed in Table 5. The endothermic property of the equilibrium system was observed as the magnitude of the enthalpy $\left(\Delta H^{\circ}\right)$ obtained, which is positive $[50,53,54]$. As such, with increasing temperatures, the adsorption percentages will grow. The entropy, $\Delta S^{\circ}$, determined was also positive. This reflected the increased degree of freedom as well as the enhanced randomness at the adsorbent-adsorbate interface. Gibbs-free energy change, $\Delta G^{\circ}$, was negative. Therefore, it can be concluded that the sorption process observed in this scenario for LFP-300 and HC-300 was feasible and spontaneous [52]. 
Table 5. Thermodynamic parameters of $\mathrm{Pb}$ (II) adsorption for LFP-300 and HC-300.

\begin{tabular}{|c|c|c|c|c|c|}
\hline Sample & Temperature, ${ }^{\circ} \mathrm{K}$ & $\Delta G^{\circ}\left(\mathrm{KJ}-\mathrm{mol}^{-1}\right)$ & $\Delta H^{\circ}\left(\mathrm{KJ}^{\prime} \mathrm{mol}^{-1}\right)$ & $\Delta S^{\circ}\left(\mathrm{JK}^{-1} \mathrm{~mol}^{-1}\right)$ & $R^{2}$ \\
\hline \multirow{3}{*}{ LFP-300 } & 303 & -4.526 & +25.870 & +0.0702 & 0.9821 \\
\hline & 323 & -4.009 & & & \\
\hline & 343 & -3.118 & & & \\
\hline \multirow{3}{*}{ HC-300 } & 303 & -4.477 & +23.462 & +0.0624 & 0.981 \\
\hline & 323 & -4.021 & & & \\
\hline & 343 & -3.219 & & & \\
\hline
\end{tabular}

\section{Materials and Methods}

\subsection{Grinding and Sieving of Dimocarpus longan Peel (LFP)}

The fruits of Dimocarpus longan were purchased from a local market in Malacca, Malaysia. The mesocarp of the fruits were separated from the peel or exocarp of the longan fruits and then ground to powder. To eliminate the larger particles, the grounded LFP samples were passed through a $20 \mu \mathrm{m}$ mesh screen. After screening, the LFP powder was washed thoroughly with deionized water and dried at $90^{\circ} \mathrm{C}$ for $24 \mathrm{~h}$. The raw samples were packed in closed bottles for the initial characterization.

\subsection{Delignification of Dimocarpus longan Peel (LFP)}

The pectin, gum, and wax were first removed from the LFP powder by using a Soxhlet extractor (Z556203, Sigma Aldrich, and Kuala Lumpur, Malaysia). At first, the LFP powder was mixed with a 2:1 solution of benzene/ethanol $(v / v)$ solvent at $75^{\circ} \mathrm{C}$ for $4 \mathrm{~h}$. The sample was filtered and dried for $6 \mathrm{~h}$ at $60{ }^{\circ} \mathrm{C}$. To ensure complete delignification, microwave assisted alkali pretreatment was carried out. $2.5 \mathrm{M} \mathrm{NaOH}$ was mixed with the sample where the LFP powder to solvent ratio was kept at 1:30 under microwave irradiation. The power of the microwave was kept constant at $150 \mathrm{~W}$. Under microwave irradiation, it was kept for $90 \mathrm{~min}$ at $65^{\circ} \mathrm{C}$. After cooling, the filter cake was washed with de-ionized water to remove excess alkali and dried in an oven at $55^{\circ} \mathrm{C}$ for $4 \mathrm{~h}$. The light brown mass $(1 \mathrm{gm})$ obtained was bleached using $50 \mathrm{~mL}$ solution of $30 \%$ hydrogen peroxide $\left(\mathrm{H}_{2} \mathrm{O}_{2}\right)$ for $4 \mathrm{~h}$ at $60^{\circ} \mathrm{C}$. Then the sample obtained was labeled as holocellulose (HC) and was repetitively washed again with hot deionized water and oven-dried at $80^{\circ} \mathrm{C}$. The $\mathrm{HC}$ sample obtained was stored in an airtight container for further characterization.

\subsection{Hydrothermal Carbonization of HC and LFP}

A total of $5 \mathrm{~g}$ of holocellulose (HC) and raw LFP powder was added to $50 \mathrm{~mL}$ of deionized water. The mixture was subsequently placed inside a Teflon-lined steel autoclave with a $100-\mathrm{mL}$ capacity. The mixture was sealed and heated at temperatures ranging from $200{ }^{\circ} \mathrm{C}$ to $300^{\circ} \mathrm{C}$ for $24 \mathrm{~h}$. The mixture was allowed to cool at room temperature. The resulting carbonaceous materials were filtered off and washed several times with deionized water. Lastly, the sample was oven-dried at $80^{\circ} \mathrm{C}$ for $6 \mathrm{~h}$. The resulting sample was labeled according to the starting precursors and treatment temperatures used, which included LFP-200, LFP-250, and LFP-300 for the raw Dimocarpus longan peel samples and HC-200, HC-250, and HC-300 for HC-based carbon samples, respectively.

\subsection{Synthesis of Carbon Micro-Spheres and Physical and Electro-Chemical Characterizations}

The raw biomass of Dimocarpus longan (LFP) peel and the extracted HC along with the prepared hydrochar samples were characterized by a CHNOS elemental analyzer (PerkinElmer-2400, Tokyo, Japan). Next, thermo-gravimetric analysis (TGA) coupled with a differential thermal analyzer (DTA; Mettler Toledo Star SW901, Tokyo, Japan) was performed to check the thermal stability of the samples under a nitrogen flow rate of $5 \mathrm{~mL} / \mathrm{min}$. For the TGA analysis, $5 \mathrm{mg}$ of each sample were taken and 
heated to $800{ }^{\circ} \mathrm{C}$ at a heating rate of $5{ }^{\circ} \mathrm{C} / \mathrm{min}$. The fixed carbon content after TGA analysis was estimated by using Equation (7) [55].

$$
\text { Fixed Carbon }(\%)=100-(\text { Moisture } \%+\text { ash } \%+\text { Volatile matter } \%)
$$

The solid carbonaceous product yield after hydrothermal carbonization was determined using Equation (8).

$$
\text { Yield }(\%)=\frac{W_{2}}{W_{1}} \times 100
$$

where, $W_{1}$ is the dry weight of the starting sample prior to the treatment $(\mathrm{g})$ and $\mathrm{W}_{2}$ is the final carbonaceous substances' weight (g) [36].

The theoretical higher heating value (HHV predicted) was calculated using an equation from Channiwala and Parikh (2002). Equation (9) is shown below.

$$
H H V_{\text {predicted }}\left(\mathrm{MJKg}^{-1}\right)=0.3491 \mathrm{C}+1.1783 \mathrm{H}+0.1005 \mathrm{~S}-0.1034 \mathrm{O}-0.0015 \mathrm{~N}-0.0211 \mathrm{~A}
$$

where, $\mathrm{C}, \mathrm{H}, \mathrm{S}, \mathrm{O}, \mathrm{N}$, and A represent the weight percentages of carbon, hydrogen, sulfur, oxygen, nitrogen, and ash in carbon, respectively [56]. This equation has been used by previous researchers and the relative error between the calculated and predicted values is less than $6 \%[57,58]$. The $\mathrm{pH}$ and electrical conductivity (EC) were measured using the method described in other literature [59]. At first suspensions of $0.01 \mathrm{M}$ calcium chloride, $\mathrm{CaCl}_{2}$ and distilled $\mathrm{H}_{2} \mathrm{O}(1: 5 \mathrm{v} / \mathrm{v})$ were prepared and $1 \mathrm{~g}$ of carbon sample was added. The mixtures were shaken for $1 \mathrm{~h}$ on a low-speed shaker at room temperature. After sedimentation of the carbonaceous material for an additional hour, the $\mathrm{pH}$ and EC were determined in the supernatant [32]. X-ray diffraction (XRD) patterns of the raw samples and the carbon samples were examined using a D5005 (Bruker, Berlin, Germany) at $40 \mathrm{kV}$ and $40 \mathrm{~mA}$ with Cu and $\mathrm{K} \alpha$ radiation. The percentage crystallinity can be calculated by using the equation below $[60,61]$.

$$
C=\frac{I_{002}-I_{a m}}{I_{002}} \times 100
$$

where, $I_{002}$ is the maximum intensity of peak 002 at $2 \theta=22.5^{\circ}, I_{a m}$ is the intensity at $2 \theta=18.0^{\circ}$, and $C$ is the crystallinity index $[60,61]$.

A scanning electron microscope (SEM, Model Leo Supra50VP Field Emission, London, UK) was used to obtain the morphological features of the prepared carbons with the raw wood sample. The BET surface area, pore volume, and pore size distribution of the prepared carbon spheres were analyzed with an Autosorb1: Quantachrome Autosorb automated gas sorption system supplied by Quantachrome (Berlin, Germany). The BET equation was used to calculate the surface area of the hydrochar.

\subsection{Equilibrium Adsorption Isotherm and Thermodynamics Studies}

$50 \mathrm{~mL}$ solution of $\mathrm{Pb}(\mathrm{II})$ cations with concentrations of $25 \mathrm{ppm}, 50 \mathrm{ppm}, 70 \mathrm{ppm}, 90 \mathrm{ppm}, 100 \mathrm{ppm}$, and $150 \mathrm{ppm}$ were placed inside the conical flasks. A total of $0.25 \mathrm{~g}$ of synthesized carbon microspheres were added to the solution. The solutions were agitated at $200 \mathrm{rpm}$ for different temperatures of $30^{\circ} \mathrm{C}$, $40{ }^{\circ} \mathrm{C}$, and $50{ }^{\circ} \mathrm{C}$. The $\mathrm{pH}$ of the water samples were adjusted to 5.5. After the system has reached equilibrium within $6 \mathrm{~h}$, the water samples were withdrawn and filtered to separate the carbon sample. The filtrate was analyzed to measure residual metal ion concentration. The following equation was used to calculate the amount adsorbed onto the surface of the carbon spheres [50,52-54].

$$
q_{e}=\frac{\left(C_{0}-C_{e}\right) V}{W}
$$


In the equation above, $q_{e}(\mathrm{mg} / \mathrm{g})$ shows the amount of ion adsorbed onto the surface of the carbon at equilibrium. $C_{0}$ is the initial metal ion concentration and $C_{e}(\mathrm{mg} / \mathrm{L})$ is the liquid-phase concentrations of $\mathrm{Pb}(\mathrm{II})$ ions at equilibrium conditions. $V(\mathrm{~L})$ is the volume of the synthetic solution and $W(\mathrm{~g})$ is the mass of the carbon sample [50,52]. Experimental data was fitted with the linear isotherm models of Langmuir, Freundlich, and Temkin. Thermodynamic calculation was done to determine the values of $\Delta G, \Delta H$, and $\Delta S$ of the equilibrium system using the Sigma Plot, version 15.

\section{Conclusions}

This study investigated the potential of raw Dimocarpus longan peel (LFP) and HC made from the LFP to produce micro-spherical carbon using a hydrothermal carbonization technique. The effect of the carbonization temperature on the energy content as well as physical and electro-chemical properties of the synthesized carbon was evaluated. The carbon yield decreased greatly for both the precursors when the HTC temperature was increased from $200{ }^{\circ} \mathrm{C}$ to $300{ }^{\circ} \mathrm{C}$. The HTC temperature extensively influenced the physicochemical characteristics of the prepared carbon spheres. An increase in temperature enhanced the proportion of the carbon substantially while the oxygen and hydrogen content of the carbon sample decreased. A rise in temperature enhanced the BET surface area and changed the porous texture of the synthesized carbon sample. This showed that porosity was not developed sufficiently during the HTC process. The XRD pattern clearly revealed that the crystalline region of the cellulose in the $\mathrm{HC}$-based carbon spheres was destroyed at $250{ }^{\circ} \mathrm{C}$. The crystalline structure of the cellulose in the HC-based char can be easily destroyed and carbonized without the shielding effect of lignin. The amorphous texture of carbon was observed at $300{ }^{\circ} \mathrm{C}$ for the LFP-based carbon sample. After delignification, the HC extract showed less thermal stability than the LFP peel powder. The presence of the hemicellulose and cellulose biopolymer embedded inside the lignin was more challenging to degrade thermally. The high aromaticity of lignin provided resistance for the LFP powder, which was easily degraded. The amount of energy content determined in HC-derived carbon spheres was greater than the LFP peel powder based on HTC samples. Equilibrium data were well fitted with the Langmuir isotherm for LFP-300 and HC-300. The Langmuir monolayer adsorption capacity rose with the increasing trend of temperature. LFP-300 had shown more monolayer adsorption capacity than the HC-300 sample due to its larger surface area. The thermodynamic profile of the equilibrium system suggested an endothermic nature as well as feasibility of the sorption process.

Author Contributions: S.S. and Z.Z.C. conceived and designed the experiments. A.A.K., S.T.S., and B.K. had performed the experiments. Y.K.A., Z.Z.C., and R.F.R. analyzed the data. S.N.K. and R.B.J. had contributed reagents/materials/analysis tools. Z.Z.C., N.A., and Y.A.W. had written the paper.

Funding: This research received no External Funding.

Acknowledgments: The authors are thankful for the funding provided by Grant No. RP044C-17AET and RP044D-17AET from the University of Malaya, Malaysia. The authors are also grateful for using the testing lab facilities of AMET University, Chennai, India and The State University of New Jersey, USA. One of the authors, Suresh Sagadevan is also affiliated as "Visiting Fellow" at the Department of Physics, Center for Defence Foundation Studies, National Defence University of Malaysia, Kem Sg. Besi, 57000 Kuala Lumpur, Malaysia. The author wishes to thanks to the authorities concerned where the research work has been partially conducted.

Conflicts of Interest: The authors declare no conflict of interest.

\section{References}

1. Rizhikovs, J.; Zandersons, J.; Spince, B.; Dobele, G.; Jakab, E. Preparation of granular activated carbon from hydrothermally treated and pelletized deciduous wood. J. Anal. Appl. Pyrol. 2011, 93, 68-76. [CrossRef]

2. Robbins, M.P.; Evans, G.; Valentine, J.; Donnison, I.; Allison, G. New opportunities for the exploitation of energy crops by thermochemical conversion in Northern Europe and the UK. Prog. Energy Combust. Sci. 2012, 38, 138-155. [CrossRef]

3. Luque, R.; Sudipta, D.; Alina, M.B. Catalytic Conversion of Biomass. Catalysts 2016, 6, 148. [CrossRef] 
4. Titirici, M.M.; Thomas, A.; Yu, S.H.; Müller, J.; Antonietti, M. A direct synthesis of mesoporous carbons with bi-continuous pore morphology from crude plant material by hydrothermal carbonization. Chem. Mater. 2007, 19, 4205-4212. [CrossRef]

5. Titirici, M.M.; Antonietti, M.; Baccile, N. Hydrothermal carbon from biomass: A comparison of the local structure from poly-to monosaccharides and pentoses/hexoses. Green Chem. 2008, 10, 1204-1212. [CrossRef]

6. Sevilla, M.; Fuertes, A.B. The production of carbon materials by hydrothermal carbonization of cellulose. Carbon 2009, 47, 2281-2289. [CrossRef]

7. Sevilla, M.; Fuertes, A.B.; Mokaya, R. High density hydrogen storage in superactivated carbons from hydrothermally carbonized renewable organic materials. Energy Environ. Sci. 2011, 4, 1400-1410. [CrossRef]

8. Chowdhury, Z.Z.; Hamid, S.B.A.; Rahman, M.M.; Rafique, R.F. Catalytic activation and application of micro-spherical carbon derived from hydrothermal carbonization of lignocellulosic biomass: Statistical analysis using Box-Behnken design. RSC Adv. 2016, 6, 102680-102694. [CrossRef]

9. Gao, Y.; Chen, H.; Wang, J.; Shi, T.; Yang, H.; Wang, X. Characterization of products from hydrothermal liquefaction and carbonation of biomass model compounds and real biomass. J. Fuel Technol. 2011, 39, 893-900. [CrossRef]

10. Sevilla, M.; Maciá-Agulló, J.A.; Fuertes, A.B. Hydrothermal carbonization of biomass as a route for the sequestration of $\mathrm{CO}_{2}$ : Chemical and structural properties of the carbonized products. Biomass Bioenergy 2011, 35, 3152-3159. [CrossRef]

11. Román, S.; Nabais, J.M.V.; Ledesma, B.; González, J.F.; Laginhas, C.; Titirici, M.M. Production of low-cost adsorbents with tunable surface chemistry by conjunction of hydrothermal carbonization and activation processes. Microporous Mesoporous Mater. 2013, 165, 127-133. [CrossRef]

12. Garlof, S.; Mecklenburg, M.; Smazna, D.; Mishra, Y.K.; Adelung, R.P.; Schulte, S.; Fiedler, B. 3D carbon networks and their polymer composites: Fabrication and electromechanical investigations of neat Aerographite and Aerographite-based PNCs under compressive load. Carbon 2017, 111, 103-112. [CrossRef]

13. Schütt, F.; Signetti, S.; Krüger, H.; Röder, S.; Smazna, D.; Kaps, S.; Gorb, S.N.; Mishra, Y.K.; Pugno, N.M.; Adelung, R. Hierarchical self-entangled carbon nanotube tube networks. Nat. Commun. 2018. [CrossRef] [PubMed]

14. Zhao, L.; Fan, L.Z.; Zhou, M.; Guan, H.; Qiao, S.; Antonietti, M.; Titirici, M.M. Nitrogen-containing hydrothermal carbons with superior performance in supercapacitors. Adv. Mater. 2010, 22, 5202-5206. [CrossRef] [PubMed]

15. Makowski, P.; Cakan, R.D.; Antonietti, M.; Goettmann, F.; Titirici, M. Selective partial hydrogenation of hydroxy aromatic derivatives with palladium nanoparticles supported on hydrophilic carbon. Chem. Commun. 2008, 8 , 999-1001. [CrossRef] [PubMed]

16. Xu, W.; Yu, S. Conducting performance of individual Ag@C coaxial nanocables: Ideal building blocks for interconnects in nanoscale devices. Small 2009, 5, 460-465. [CrossRef] [PubMed]

17. Bridgwater, A.V.; Meier, D.; Radlein, D. An overview of fast pyrolysis of biomass. Org. Geochem. 1999, 30, 1479-1493. [CrossRef]

18. Chowdhury, Z.Z.; Hamid, S.B.A.; Das, R.; Hasan, M.R.; Zain, S.M.; Khalid, K.; Uddin, M.N. Preparation of carbonaceous adsorbents from lignocellulosic biomass and their use in removal of contaminants from aqueous solution. BioResources 2013, 8, 6523-6555. [CrossRef]

19. Chowdhury, Z.Z.; Karim, M.Z.; Ashraf, M.A.; Khalid, K. Influence of carbonization temperature on physicochemical properties of biochar derived from slow pyrolysis of durian wood (Durio zibethinus) sawdust. BioResources 2016, 11, 3356-3372. [CrossRef]

20. Manzoli, M.; Menegazzo, F.; Signoretto, M.; Marchese, D. Biomass Derived Chemicals: Furfural Oxidative Esterification to Methyl-2-furoate over Gold Catalysts. Catalysts 2016, 6, 107. [CrossRef]

21. Falco, C.; Sieben, J.M.; Brun, N.; Sevilla, M.; van der Mauelen, T.; Morallón, E.; Cazorla-Amorós, D.; Titirici, M. Hydrothermal carbons from hemicellulose-derived aqueous hydrolysis products as electrode materials for supercapacitors. ChemSusChem 2013, 6, 374-382. [CrossRef] [PubMed]

22. Seehra, M.S.; Akkineni, L.P.; Yalamanchi, M.; Singh, V.; Poston, J. Structural characteristics of nanoparticles produced by hydrothermal pretreatment of cellulose and their applications for electrochemical hydrogen generation. Int. J. Hydrog. Energy 2012, 37, 9514-9523. [CrossRef]

23. Olofsson, K.; Bertilsson, M.; Lidén, G. A short review on SSF-An interesting process option for ethanol production from lignocellulosic feedstocks. Biotechnol. Biofuels 2008, 1, 1-14. [CrossRef] [PubMed] 
24. Huang, G.J.; Wang, B.S.; Lin, W.C.; Huang, S.S.; Lee, C.Y.; Yen, M.T.; Huang, M.H. Antioxidant and AntiInflammatory Properties of Longan (Dimocarpus longan Lour.) Pericarp. Evid.-Based Complement. Altern. Med. 2012, 2012. [CrossRef] [PubMed]

25. Pham, V.T.; Herrero, M.; Hormaza, J.I. Fruiting pattern in Longan, Dimocarpus longan: From pollination to aril development. Ann. Appl. Biol. 2016, 169, 357-368. [CrossRef]

26. Kumar, S.; Kothari, U.; Kong, L.; Lee, Y.Y.; Gupta, R.B. Hydrothermal pretreatment of switchgrass and corn stover for production of ethanol and carbon microspheres. Biomass Bioenergy 2011, 35, 956-968. [CrossRef]

27. Zhang, Y.; Yang, S.; Wu, J.Q.; Yuan, T.Q.; Sun, R.C. Preparation and characterization of lignocellulosic oil sorbent by hydrothermal treatment of Populus fiber. Materials 2014, 7, 6733-6747. [CrossRef] [PubMed]

28. Saqib, N.U.; Oh, M.; Jo, W.; Park, S.; Lee, J. Conversion of dry leaves into hydrochar through hydrothermal carbonization (HTC). J. Mater. Cycles Waste Manag. 2015, 19, 111-117. [CrossRef]

29. Hoekman, S.K.; Broch, A.; Robbins, C. Hydrothermal carbonization (HTC) of lignocellulosic biomass. Energy Fuels 2011, 25, 1802-1810. [CrossRef]

30. Liu, F.; Guo, M. Comparison of the characteristics of hydrothermal carbons derived from holocellulose and crude biomass. J. Mater. Sci. 2015, 50, 1624-1631. [CrossRef]

31. Thangalazhy-Gopakumar, S.; Adhikari, S.; Ravindran, H.; Gupta, R.B.; Fasina, O.; Tu, M.; Fernando, S.D. Physiochemical properties of bio-oil produced at various temperatures from pine wood using an auger reactor. Bioresour. Technol. 2010, 101, 8389-8395. [CrossRef] [PubMed]

32. Wiedner, K.; Naisse, C.; Rumpel, C.; Pozzi, A.; Wieczorek, P.; Glaser, B. Chemical modification of biomass residues during hydrothermal carbonization What makes the difference, temperature or feedstock? Org. Geochem. 2013, 54, 91-100. [CrossRef]

33. Baçaoui, A.; Yaacoubi, A.; Dahbi, A.; Bennouna, C.; Luu, R.P.T.; Maldonado-Hodar, F.J.; Rivera-Utrilla, J.; Moreno-Castilla, C. Optimization of conditions for the preparation of activated carbons from olive-waste cakes. Carbon 2001, 39, 425-432. [CrossRef]

34. Lua, A.C.; Yang, T. Effect of activation temperature on the textural and chemical properties of potassium hydroxide activated carbon prepared from pistachio-nut shell. J. Colloid Interface Sci. 2004, 274, 594-601. [CrossRef] [PubMed]

35. Danso-Boateng, E.; Holdich, R.G.; Shama, G.; Wheatley, A.D.; Sohail, M.; Martin, S.J. Kinetics of faecal biomass hydrothermal carbonisation for hydrochar production. Appl. Energy 2013, 111, 351-357. [CrossRef]

36. Kalderis, D.; Kotti, M.S.; Méndez, A.; Gascó, G. Characterization of hydrochars produced by hydrothermal carbonization of rice husk. Solid Earth 2014, 5, 477-483. [CrossRef]

37. Melo, L.C.A.; Coscione, A.R.; Abreu, C.A.; Puga, A.P.; Camargo, O.A. Influence of pyrolysis temperature on cadmium and zinc sorption capacity of sugar cane straw-derived biochar. BioResources 2013, 8, 4992-5004. [CrossRef]

38. Grønli, M.G.; Várhegyi, G.; Di Blasi, C. Thermogravimetric analysis and devolatilization kinetics of wood. Ind. Eng. Chem. Res. 2002, 41, 4201-4208. [CrossRef]

39. Uzun, B.B.; Pütün, A.E.; Pütün, E. Composition of products obtained via fast pyrolysis of olive-oil residue: Effect of pyrolysis temperature. J. Anal. Appl. Pyrol. 2007, 79, 147-153. [CrossRef]

40. Román, S.; Nabais, J.M.V.; Laginhas, C.; Ledesma, B.; González, J.F. Hydrothermal carbonization as an effective way of densifying the energy content of biomass. Fuel Process. Technol. 2012, 103, 78-83. [CrossRef]

41. Adebisi, A.G.; Chowdhury, Z.Z.; Abd Hamid, S.B.; Ali, M.E. Activated carbons for removal of Pb(II) and $\mathrm{Zn}$ (II) prepared by phosphoric acid activation of hydrothermally treated banana empty fruit bunch using box-Behnken design. BioResources 2016, 11, 9686-9709. [CrossRef]

42. Sun, K.; Tang, J.; Gong, Y.; Zhang, H. Characterization of potassium hydroxide (KOH) modified hydrochars from different feedstocks for enhanced removal of heavy metals from water. Environ. Sci. Pollut. R. 2015, 22, 16640-16651. [CrossRef] [PubMed]

43. Novak, J.M.; Lima, I.; Xing, B.; Gaskin, J.W.; Steiner, C.; Das, K.C.; Ahmedna, M.; Rehrah, D.; Watts, D.W.; Busscher, W.J.; et al. Characterization of designer biochar produced at different temperatures and their effects on a loamy sand. Ann. Environ. Sci. 2009, 3, 195-206.

44. Mumme, J.; Eckervogt, L.; Pielert, J.; Diakité, M.; Rupp, F.; Kern, J. Hydrothermal carbonization of anaerobically digested maize silage. Bioresour. Technol. 2011, 102, 9255-9260. [CrossRef] [PubMed] 
45. Fernandez, M.E.; Ledesma, B.; Román, S.; Bonelli, P.R.; Cukierman, A.L. Development and characterization of activated hydrochars from orange peels as potential adsorbents for emerging organic contaminants. Bioresour. Technol. 2015, 183, 221-228. [CrossRef] [PubMed]

46. Keiluweit, M.; Nico, P.S.; Johnson, M.G.; Kleber, M. Dynamic molecular structure of plant biomass-derived black carbon (biochar). Environ. Sci. Technol. 2010, 44, 1247-1253. [CrossRef] [PubMed]

47. Langmuir, I. The adsorption of gases on plane surfaces of glass, mica and platinum. J. Am. Chem. Soc. 1918, 4, 1361-1403. [CrossRef]

48. Freundlich, H.M.F. Over the adsorption in solution. J. Phys. Chem. 1906, 57, 385-471.

49. Temkin, M.J.; Pyzhev, V. Recent modification to Langmuir isotherms. Acta Physicochem. 1940, 12, $217-225$.

50. Abd Hamid, S.B.; Chowdhury, Z.Z.; Zain, S.M. Base Catalytic Approach: A Promising Technique for Activation of Bio Char for Equilibrium Sorption Studies of Copper, Cu (II) ions in Single Solute System. Materials 2014, 7, 2815-2832. [CrossRef] [PubMed]

51. Abideen, I.A.; Ofudje, A.E.; Mopelola, A.I.; Sarafadeen, O.K. Equilibrium kinetics and thermodynamics studies of the biosorption of Mn (II) ions from aqueous solution by raw and acid treated corn cob biomass. Am. J. Appl. Sci. 2011, 6, 302-309.

52. Farheen, K.; Rizwan, W.; Mohamed, H.; Rua, A.L.; Mohd, R. Nanotransition Materials (NTMs): Photocatalysis, Validated High Effective Sorbent Models Study for Organic Dye Degradation and Precise Mathematical Data's at Standardized Level. Nanomaterials 2018, 8, 134. [CrossRef]

53. Adebisi, G.A.; Chowdhury, Z.Z.; Abd Hamid, S.B.; Ali, E. Equilibrium Isotherm, Kinetic, and Thermodynamic Studies of Divalent Cation Adsorption onto Calamus gracilis Sawdust-Based Activated Carbon. BioResources 2017, 12, 2872-2898. [CrossRef]

54. Adebisi, G.A.; Chowdhury, Z.Z.; Alaba, P.A. Equilibrium, Kinetic, and Thermodynamic Studies of Lead ion and Zinc ion Adsorption from Aqueous Solution onto Activated Carbon Prepared from Palm Oil Mill Effluents. J. Clean. Prod. 2017, 148, 958-968. [CrossRef]

55. Duran-Valle, C.J.; Gomez-Corzo, M.; Pastor-Villegas, J.; Gomez-Serrano, V. Study of Cherry Stones as raw materials in preparation of carbonaceous adsorbents. J. Anal. Appl. Pyrol. 2005, 73, 59-67. [CrossRef]

56. Tongpoothorn, W.; Sriuttha, M.; Homchan, P.; Chanthai, S.; Ruangviriyachai, C. Preparation of activated carbon derived from Jatropha curcas fruit shell by simple thermo-chemical activation andcharacterization of their physico-chemical properties. Chem. Eng. Res. Des. 2011, 89, 335-340. [CrossRef]

57. Channiwala, S.A.; Parikh, P.P. A unified correlation for estimating HHV of solid, liquid, and gaseous fuels. Fuel 2002, 81, 1051-1063. [CrossRef]

58. Kang, S.; Li, X.; Fan, J.; Chang, J. Characterization of hydrochars produced by hydrothermal carbonization of lignin, cellulose, D-xylose, and wood meal. Ind. Eng. Chem. Res. 2012, 51, 9023-9031. [CrossRef]

59. Adinata, D.; Daud, W.M.A.W.; Aroua, M.K. Preparation and characterization of activated carbon from palm shell by chemical activation with $\mathrm{K}_{2} \mathrm{CO}_{3}$. Bioresour. Technol. 2007, 98, 145-149. [CrossRef] [PubMed]

60. Abd Hameed, S.B.; Chowdhury, Z.Z.; Karim, M.Z. Catalytic Extraction of Microcrystalline Cellulose (MCC) from Elaeis guineensis using Central Composite Design (CCD). BioResources 2014, 9, 7403-7426. [CrossRef]

61. Chowdhury, Z.Z.; Abd Hameed, S.B. Preparation and Characterization of Nano-crystalline Cellulose Using Ultrasonication Combined with a Microwave-assisted Pretreatment Process. BioResources 2016, 11, 397-3415. [CrossRef]

(C) 2018 by the authors. Licensee MDPI, Basel, Switzerland. This article is an open access article distributed under the terms and conditions of the Creative Commons Attribution (CC BY) license (http://creativecommons.org/licenses/by/4.0/). 